\title{
Task-shifting alcohol interventions for HIV+ Crossuat persons in Kenya: a cost-benefit analysis
}

Omar Galárraga', Burke Gao ${ }^{1,2}$, Benson N. Gakinya ${ }^{3}$, Debra A. Klein ${ }^{4}$, Richard G. Wamai ${ }^{5}$, John E. Sidle ${ }^{6}$ and Rebecca K. Papas ${ }^{7 *}$

\begin{abstract}
Background: Among HIV+ patients, alcohol use is a highly prevalent risk factor for both HIV transmission and poor adherence to HIV treatment. The large-scale implementation of effective interventions for treating alcohol problems remains a challenge in low-income countries with generalized HIV epidemics. It is essential to consider an intervention's cost-effectiveness in dollars-per-health-outcome, and the long-term economic impact —or "return on investment" in monetary terms.
\end{abstract}

Methods: We conducted a cost-benefit analysis, measuring economic return on investment, of a task-shifted cognitivebehavioral therapy (CBT) intervention delivered by paraprofessionals to reduce alcohol use in a modeled cohort of 13,440 outpatients in Kenya. In our base-case, we estimated the costs and economic benefits from a societal perspective across a six-year time horizon, with a 3\% annual discount rate. Costs included all costs associated with training and administering task-shifted CBT therapy. Benefits included the economic impact of lowered HIV incidence as well as the improvements in household and labor-force productivity. We conducted univariate and multivariate probabilistic sensitivity analyses to test the robustness of our results.

Results: Under the base case, total costs for CBT rollout was $\$ 554,000$, the value of benefits were $\$ 628,000$, and the benefit-to-cost ratio was 1.13. Sensitivity analyses showed that under most assumptions, the benefit-to-cost ratio remained above unity indicating that the intervention was cost-saving (i.e., had positive return on investment). The duration of the treatment effect most effected the results in sensitivity analyses.

Conclusions: CBT can be effectively and economically task-shifted to paraprofessionals in Kenya. The intervention can generate not only reductions in morbidity and mortality, but also economic savings for the health system in the medium and long term. The findings have implications for other countries with generalized HIV epidemics, high prevalence of alcohol consumption, and shortages of mental health professionals.

Trial registration: This paper uses data derived from "Cognitive Behavioral Treatment to Reduce Alcohol Use Among HIV-Infected Kenyans (KHBS)" with ClinicalTrials.gov registration NCT00792519 on 11/17/2008; and preliminary data from "A Stage 2 Cognitive-behavioral Trial: Reduce Alcohol First in Kenya Intervention" (NCT01503255, registered on 12/16/2011).

Keywords: Task-shifting, Alcohol, Cognitive-behavioral-therapy, CBT, HIV, AIDS, Cost-benefit-analysis, Kenya, Sub-Saharan Africa

\footnotetext{
* Correspondence: rebecca_papas@brown.edu

${ }^{7}$ Department of Psychiatry and Human Behavior, Brown University Alpert

Medical School, Providence, RI 02912, USA

Full list of author information is available at the end of the article
}

\section{Ciömed Central}

(c) The Author(s). 2017 Open Access This article is distributed under the terms of the Creative Commons Attribution 4.0 International License (http://creativecommons.org/licenses/by/4.0/), which permits unrestricted use, distribution, and reproduction in any medium, provided you give appropriate credit to the original author(s) and the source, provide a link to the Creative Commons license, and indicate if changes were made. The Creative Commons Public Domain Dedication waiver (http://creativecommons.org/publicdomain/zero/1.0/) applies to the data made available in this article, unless otherwise stated. 


\section{Background}

Alcohol use is responsible for $13.5 \%$ of global deaths due to infectious diseases including HIV, and $5.1 \%$ of disability-adjusted life years (DALYs) $[1,2]$. The high worldwide alcohol use related morbidity and mortality suggests an urgent need for a global focus on treatment of alcohol use disorders [3-5]. Alcohol consumption negatively impacts the effectiveness of prevention efforts by facilitating HIV transmission through increased sexual risk behavior as well as HIV treatment non-adherence [6-11]. Although dramatic progress against HIV/AIDS has been made in sub-Saharan Africa [12] -with disease incidence decreasing by $25 \%$ in 22 countries from 1990 to 2009 and treatment access expanding from 50,000 to over 5 million persons from 2002 to 2012 [13] - the progress towards "zero new infections and zero AIDSrelated deaths" promoted by UNAIDS [14] is hampered by several challenges. These include the growing HIV prevalence due to expanded lifespans, limited accessibility to antiretrovirals (ARVs), and continued suboptimal adherence to treatment $[13,14]$. While increased access to ARVs improves overall health by lowering viral load and acting as a protective factor $[15,16]$, the predictive ability of adherence $[17,18]$ is strongly mediated by alcohol use $[8,19-23]$. This suggests that alcohol use can present a significant barrier to the Zero Campaign by increasing HIV infectivity. The evidence suggests a linear dose-response relationship between alcohol use and risk for comorbid and AIDS-defining illnesses [24]. That is, although high levels of alcohol use are associated with higher rates of AIDSrelated complications and higher health care costs, any level of alcohol use places a patient at higher risk for such complications and higher costs-thus suggesting that there is no "safe" level of alcohol consumption for HIV-infected patients. For this reason, we consider alcohol use of all levels as harmful for $\mathrm{HIV}+$ persons throughout this paper.

In sub-Saharan Africa, Kenya is among countries with high and hazardous alcohol consumption, $22.7 \%$ of adults (age 15+) using alcohol within the past 12 months, and an estimated 3.2\% of adults (age 15+) exhibiting alcohol use disorders [2]. Furthermore in a survey among school-going Kenyan youth, 48.9\% have drunk alcohol [25]. Because harmful alcohol use behavior is classified as a mental health disorder, known as alcohol use disorder (or AUD), and because such behavior can be associated with spread of HIV [9, 26-28], it is important that those with AUD receive appropriate mental health treatment. Unfortunately, throughout much of the world, there exists a large treatment gap between psychiatric service availability and the high burden of mental disorders including substance abuse [29]. In Kenya in particular, the Ministry of Health reports that $20-30 \%$ outpatient visits are for mental disorders [30], and only $15 \%$ of mental health patients receive treatment [31]. Furthermore, despite an estimated 25\% of patients in general health clinics suffering from alcohol and substance abuse disorders, only $0.1 \%$ of patients in general health clinics had their alcohol abuse problems picked up by clinicians [31]. This is likely because of the dearth of mental health care workers. In 2010, Kenya employed approximately 75 psychiatrists, only 12 of whom work across the eight provincial and 250 district hospital system - one psychiatrist for every province of 3-5 million people [32]. There were 250 trained psychiatric nurses deployed in psychiatry in Kenya, so approximately one psychiatric nurse per 160,000 Kenyans [32]. In the current context of acute shortages of specialist health workers, high alcohol use, and high HIV prevalence [33-35], there are calls for innovative cost-effective strategies to reduce alcohol use in sub-Saharan Africa, and in Kenya in particular [36, 37].

One promising model to accelerate delivery is taskshifting of services in which tasks performed by professionals are delegated to those with less formal education or training called paraprofessionals [38-41]. Shifting of mental health services through training additional personnel could be critical to meet demand [32, 42]. Task-shifting to scale-up other HIV prevention interventions in Kenya offers a practical model for healthcare delivery [43]. Task-shifting HIV and alcohol interventions may promote behavior change among larger numbers of people living with HIV, including men who generally utilize less HIV testing, less therapy and display lower adherence to care [44-46].

Given the limited number of mental health professionals in Kenya, we developed a cognitive behavioral therapy (CBT) to reduce alcohol consumption, and a framework of paraprofessional training and supervision to task-shift this CBT. CBT has been shown to positively influence health behavior by engaging participants in a deliberate exploration of thoughts, actions and feelings by which participants learn coping skills to handle high-risk substance use situations [47]. CBT was selected for the Kenyan adaptation because of its strong empirical support in both individual and group formats to reduce substance abuse $[48,49]$, durability of treatment effects, and prior successful applications in sub-Saharan Africa to reduce risky sexual behaviors among HIV-infected Zambian couples [50] and to improve mood among Nigerian surgical patients [51]. Furthermore, because of its highly-structured format, CBT was feasible for training paraprofessionals and for delivery to those with limited formal education. On the contrary, using Medication Assisted Therapy (MAT) was not feasible in this resource-limited setting due to extremely limited health care professionals to deliver or monitor the medication. Additionally, MAT typically requires longer delivery to curb alcohol use, recommended from 4 months [52] up to 12 months or longer [53]. 
In a previous pilot study, we found task-shifted CBT to be effective at reducing alcohol use, with a reported alcohol abstinence rate of $69 \%$ at a 90 day follow-up (vs. $38 \%$ usual care) $[47,54]$. As mentioned earlier, all levels of alcohol use-even low levels-have been shown to have a negative impact on HIV+ persons [24]. Therefore, our pilot study included any HIV+ patients who had any amount of alcohol in the previous month, as well as a score of 3 on AUDIT-C or endorsement of binge drinking on a monthly basis. Furthermore, the level of competency of this task-shifted CBT was independently rated to be equivalent to therapy delivered by college-educated therapists in the U.S. [47, 54].

The present economic evaluation study has three aims. First, we describe field-based costs of a feasible rollout of CBT to reduce alcohol use among 13,440 HIV-infected outpatients at 12 sites in Kenya. Our assumptions are based on two CBT trials in western Kenya [47, 54]. Second, we estimate the potential economic benefits of the rollout in medium- and long-term based on simulation methods. Third, we calculate the potential medium to long-term benefit-to-cost ratio (BCR).

We chose to conduct a cost-benefit analysis for two reasons. First, previous research suggests that CBT may be cost-effective in the Kenyan context, but cost-saving only under very strict assumptions [37]. We hypothesized that including the additional potential economic impact of the CBT intervention in the Kenyan setting would provide a more comprehensive assessment. Thus, cost-benefit analysis (comparing both costs and all benefits in monetary terms) would be better suited for illustrating this point than cost-effectiveness analysis (which compares costs in monetary terms, and effects given only as health outcomes) or cost-utility analysis (which uses cost per utility effect such as dollar per quality-adjusted life year) $[55,56]$. To show that CBT is effective and cost-saving is not a trivial task because only a few interventions are highly-effective and also save costs [57]. Second, modelling based on effectiveness outcomes alone has already been completed using our CBT estimates [36], making costbenefit analysis (that includes monetary evaluation of health and economic benefits) the next logical step in this line of research. Our cost-benefit analysis offers useful novel information regarding the health and economic benefits of CBT.

\section{Methods}

A cost-benefit analysis is an economic evaluation technique which places a monetary valuation on a health program's costs and benefits, allowing for the comparison of a health program's incremental cost to its incremental benefits in corresponding monetary units [58]. The model presented in this paper estimates the costs and benefits of rolling out a task-shifted CBT intervention to reduce alcohol use among persons living with HIV in Kenya from a societal perspective, including beneficial economic impact over and above reductions in mortality and morbidity. Benefits included those associated with lowered HIV incidence and improvements in household as well as labor force productivity (Table 1). Costs included all costs associated with training and administering task-shifted CBT (Tables 2 and 3). There is inherent uncertainty when placing a monetary valuation on a program's potential future costs and benefits. To help account for this uncertainty we created sensitivity analyses which vary our model's key assumptions across different ranges as described in the Sensitivity analyses section of this paper.

Our program implementation model, based on field operations and expert consultation, contemplates a program that services 13,440 participants in 12 sites in Kenya across five years. In our base case, we assume the CBT treatment effect is maintained for two years, meaning that for every year which the intervention is rolled out, the participants of that year gain benefits associated with CBT for two years. Thus in our base case, we assume a 6-year time horizon. The program's rollout was constructed from parameters based on our pilot experience in Eldoret, Kenya among $75 \mathrm{HIV}$ infected outpatients who reported hazardous or binge drinking, and our on-going randomized controlled efficacy trial with 614 randomized participants. The results, a full description of the pilot study, and an on-going trial are described elsewhere $[47,54,59]$.

Methods for rollout were based on our previous work, with some modifications to enhance future sustainability $[47,54]$. For example, while the pilot study was conducted in a large town (Eldoret) with a tertiary care medical center, our costs and methods for the rollout are based on delivering the intervention at the level of district or local hospital administered by the Ministry of Health. While paraprofessionals in our previous work possessed varying degrees of formal training from high school diploma to a bachelor's degree, salaries and training in the rollout are based on high school diploma only, to make the intervention more realistic. Though we condensed the training period from 4 to 2 weeks in this exercise, we also extended the paraprofessional counselor consultation up to one year. Whereas a psychiatrist managed safety concerns (i.e., psychiatric risk and alcohol withdrawal symptoms) in our previous studies, our rollout methods are based on training diploma nurses to manage safety issues. Finally, while our past groups were delivered by gender-matched paraprofessionals, gender of the counselor in same-gender rollout group may not be always matched. Our rollout estimates are conservatively based on two counselors at each of 12 sites delivering two groups per week with eight same-gender participants per group, amounting to an annual workload of two counselors at each site would be 
Table 1 Input parameters to model costs and benefits (per CBT participant)

\begin{tabular}{|c|c|c|c|}
\hline Parameter & Value & Range & Sources/Reference \\
\hline Benefit 1: Decreased incidence of HIV & $\$ 41$ & $\$ 39$ to $\$ 43$ & See Table 2 and Table 3 \\
\hline \multicolumn{4}{|l|}{ Efficacy of alcohol intervention: } \\
\hline $\begin{array}{l}\text { Percentage of patients reporting abstinence at } 90 \text { day } \\
\text { follow-up (CBT intervention) }\end{array}$ & $69 \%$ & & [54] \\
\hline $\begin{array}{l}\text { Percentage of patients reporting abstinence at } 90 \text { day } \\
\text { follow-up (Usual Care) }\end{array}$ & $38 \%$ & & [54] \\
\hline $\begin{array}{l}\text { Difference between intervention and usual care in percentage of } \\
\text { patients reporting abstinence at } 90 \text { day follow-up (parameter 1.1) }\end{array}$ & $31 \%$ & $21 \%$ to $41 \%$ & \\
\hline $\begin{array}{l}\text { Percentage of HIV incidence attributable to alcohol } \\
\text { consumption (parameter 1.2) }\end{array}$ & $13 \%$ & 1.8 to $16.5 \%$ & [86] \\
\hline \multicolumn{4}{|l|}{ Consumer Price Index/Inflation Rates: } \\
\hline Average 2009 Kenyan CPI & 100 & & [60] \\
\hline Average 2010 Kenyan CPI & 106.265 & & \\
\hline Average 2011 Kenyan CPI & 121.17 & & \\
\hline Average 2013 Kenyan CPI & 140.103 & & \\
\hline \multicolumn{4}{|l|}{ Costs of treating new case of HIV: } \\
\hline \multicolumn{4}{|l|}{ Average non-drug related costs (2009 USD) } \\
\hline Lab tests & 32 & 29.2 to 36.2 & [66] \\
\hline Visits & 24 & 18.8 to 29.2 & \\
\hline Support services & 0.4 & 0.10 to 0.90 & \\
\hline Fixed costs & 32 & 22.4 to 46.6 & \\
\hline Sum of mean non-drug related costs (2013 USD) & 124 & & [66] \\
\hline \multicolumn{4}{|l|}{ Median drug costs in USD: } \\
\hline 12 Month tenofovir/3TC/EFV drug regimen (2013 price) & 145.47 & $145.47-280.72$ & [68] \\
\hline \multicolumn{4}{|l|}{ Benefit 2: Increased Productivity } \\
\hline \multicolumn{4}{|l|}{ Labor Force Participation: } \\
\hline Average Monthly Min Wages (parameter 2.4 for LFP hours), USD (KES) & $76.93(6503)$ & 57.42 to 103.60 (4854 to 8757$)$ & [87] \\
\hline $\begin{array}{l}\text { Percentage rise in weekly hours worked after ARV treatment } \\
\text { (LFP hours for parameter 2.3) }\end{array}$ & $19 \%$ & $\begin{array}{l}3.7 \% \text { to } 34 \% \text { (Normal Distribution, } \\
\mathrm{SE}=1.88, \text { Mean }=4.6 \text {, Baseline total } \\
\text { hours }=24.3 \text { ) }\end{array}$ & [74] \\
\hline \multicolumn{4}{|l|}{ Household Productivity: } \\
\hline \multicolumn{4}{|l|}{$\begin{array}{l}\text { Increase in female hours spent collecting parameter in past week: } \\
\text { (HP hours for parameter 2.3) }\end{array}$} \\
\hline Firewood & 1.056 & $\begin{array}{l}0.15 \text { to } 1.96 \text { (Normal distribution, } \\
\mathrm{SE}=0.461 \text { ) }\end{array}$ & [78] \\
\hline Water & 1.945 & $\begin{array}{l}0.86 \text { to } 3.03 \text { (Normal distribution, } \\
\mathrm{SE}=0.556 \text { ) }\end{array}$ & [78] \\
\hline $\begin{array}{l}\text { Average Hourly Min Wage for House Worker (parameter } 2.4 \text { for } \\
\text { HP hours), USD (KES) }\end{array}$ & $0.85(72)$ & 0.58 to $1.03(49-87)$ & [87] \\
\hline \multicolumn{4}{|l|}{ Increase in ARV adherence due to increased abstinence: } \\
\hline Hazardous Drinkers (number of patients non-adherent/exposed) & $27.54 \%(19 / 69)$ & & [7] \\
\hline Non-Drinkers (number of patients non-adherent/exposed) & $7.78 \%(112 / 1439)$ & & [7] \\
\hline $\begin{array}{l}\text { Increase in the likelihood that an HIV+ patient which moves from } \\
\text { non-abstinence to abstinence behavior will be ARV-adherent } \\
\text { (parameter 2.2) }\end{array}$ & $19.75 \%$ & $14.75 \%$ to $24.75 \%$ & $\begin{array}{l}\text { Calculated from above } \\
\text { values }\end{array}$ \\
\hline Currency Exchange (1USD: KES) & 84.53 & & [61] \\
\hline
\end{tabular}




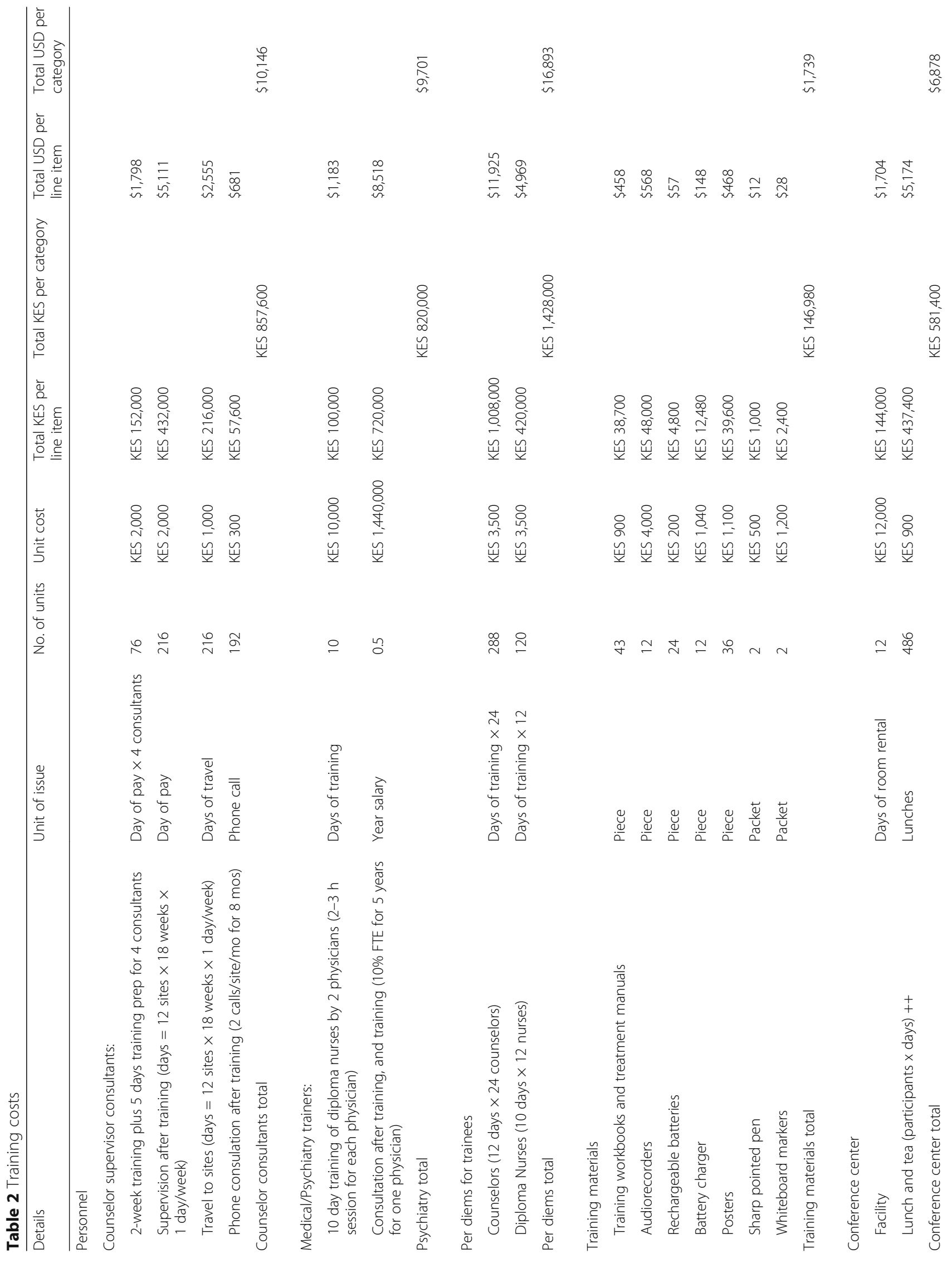




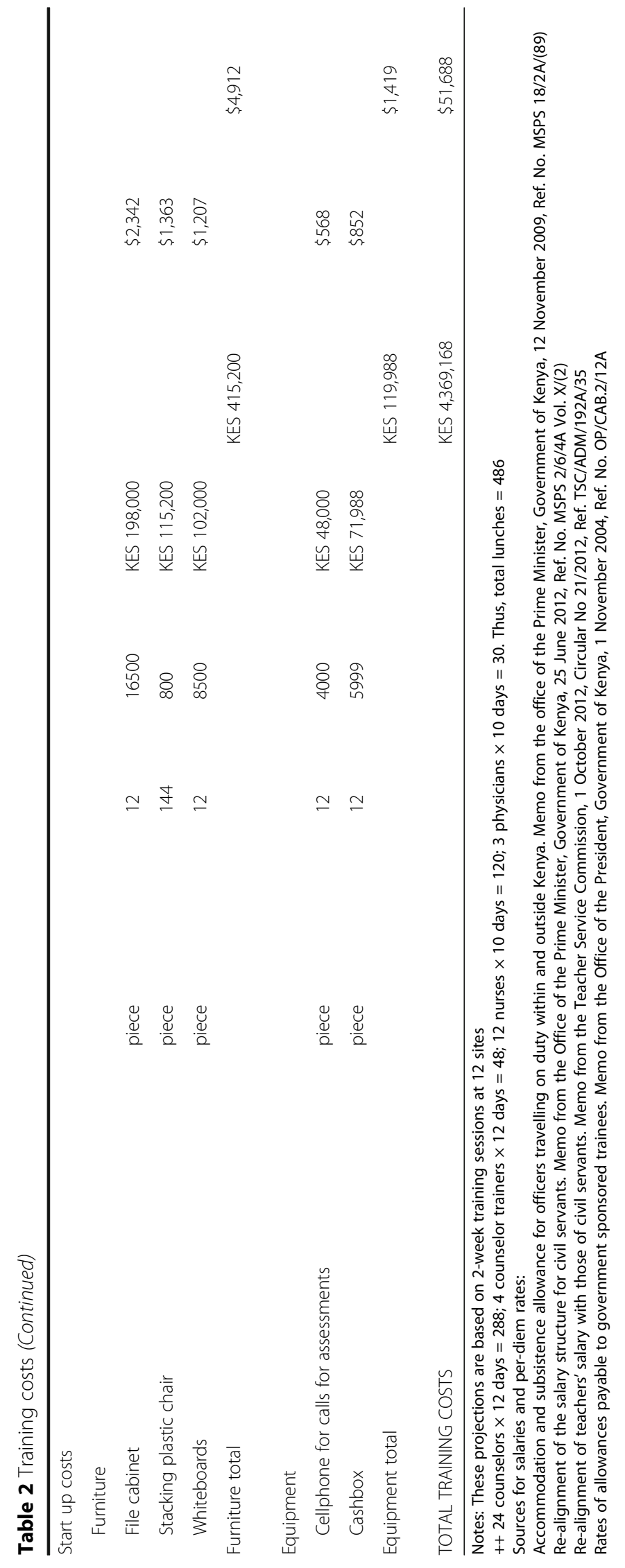




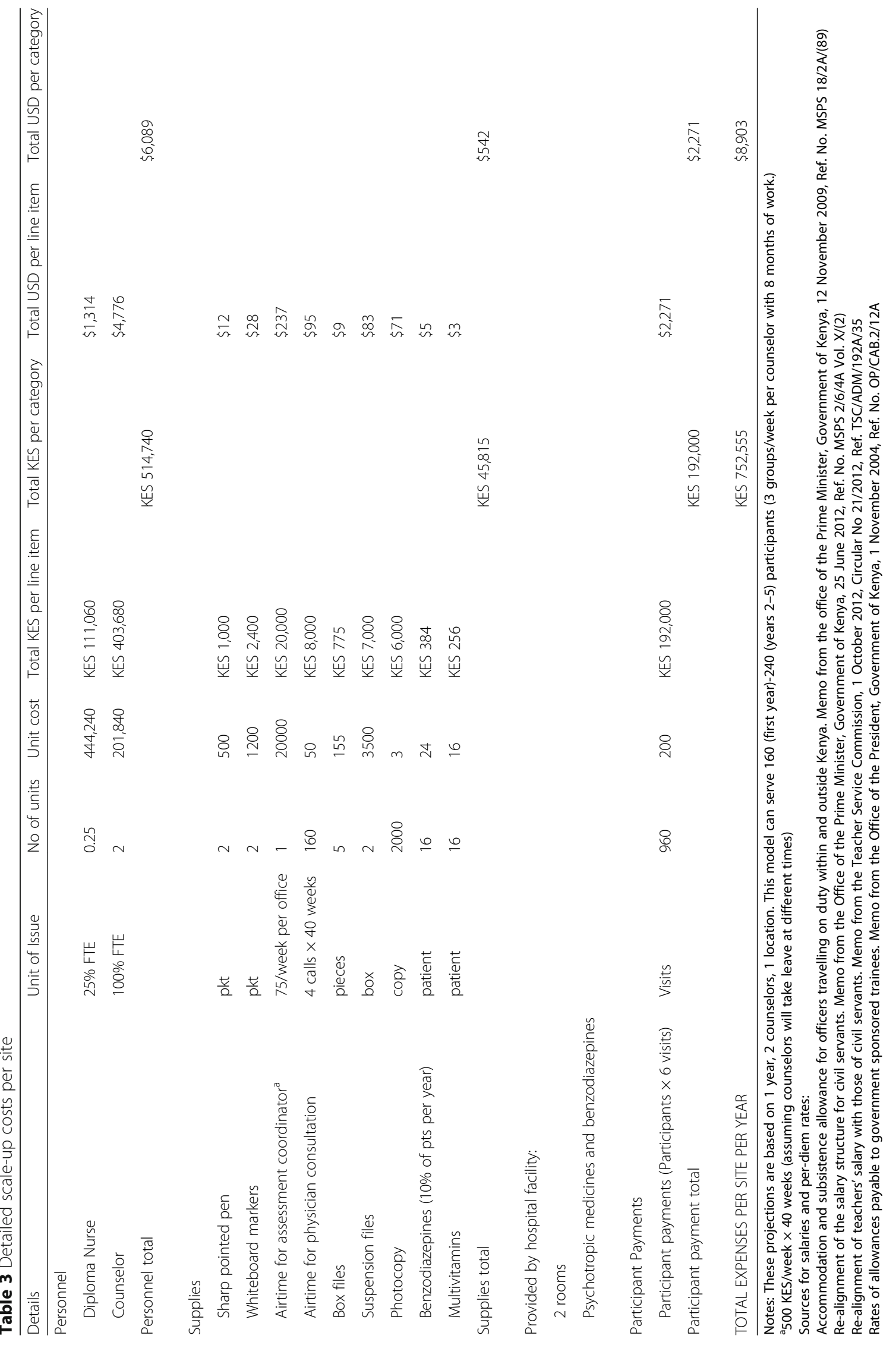


160 participants per site in year one. In years $2-5$, the counselors are projected to have gained the training and experience to handle three groups per week, amounting to 320 participants per site. We have added monthly "maintenance" groups of post-CBT patients who would like to maintain or sharpen behavioral skills. We have reduced the rate of transport reimbursement per participant because of the rollout to more proximal location to participants, and we examine a wide range of transport reimbursement rates in our sensitivity analyses. Program evaluation methods would be left to each site and could be accomplished by providing a brief measure of alcohol use (e.g., AUDIT) before and after intervention participation.

\section{Inflation, exchange rate, discounting, and benefit-to-cost ratio}

Benefits and costs were transformed into constant 2013 USD using the Kenyan consumer price index [60] and the average Kenyan shillings (KES) to U.S. dollar (USD) international exchange rate [61]. The value of all future benefits and costs were discounted at $3 \%$ per year. A benefit-to-cost ratio (BCR) was found by dividing the total discounted value of the benefits of CBT, by the total discounted value of the costs of CBT.

\section{Costs}

Training costs in the first year included standard salaries in the communities, per diems for those attending trainings or traveling for work, and a housing allowance, with rates set by Kenyan government. Costs per site per year for the CBT rollout included personnel, furniture, equipment, supplies and participant transport reimbursement. Based on available resources at district and local hospitals, we assumed free provision of a space for the counselors, a group room, and access to limited psychotropic medications and benzodiazepines. In our rollout, counselors would be employed full-time, and diploma nurses part-time at $25 \%$. For the base case scenario, participant transport reimbursement was set at $200 \mathrm{KES}$ at each visit.

\section{Total and unit project costs}

We estimated the total rollout project costs by adding the total training costs and the cost per site for 12 sites, discounted future costs (i.e., costs in years 2 to 5 ), and then divided by the number of projected participants across all 12 sites to obtain a per-participant unit cost.

\section{Benefits}

We first measured the value of the economic benefits for a single outpatient over one year, then discounted this value over future years and summed the discounted benefits across all 13,440 CBT participants. This sum was subsequently employed as the numerator in our benefit-cost ratio.

\section{Benefit 1: lowered HIV incidence}

Alcohol consumption has been shown to increase the spread of HIV infection [27, 37, 62-65]. A recent study by Braithwaite et al. showed that alcohol use was responsible for an estimated 13\% of new HIV infections; specifically citing our task-shifted pilot model and estimating that it could prevent nearly half of these new HIV infections caused by alcohol use [36]. Thus by lowering alcohol consumption, the CBT intervention would avert a large percentage of new HIV infections, and could in turn create future savings in terms of averted medically-related costs.

We modeled the annual savings accrued through averted costs from reduced likelihood of HIV transmission per HIV-negative patient as the multiplication product of:

1. The likelihood that a CBT-treated patient will exhibit abstinence for a year (parameter 1.1)

2. The reduced likelihood that an HIV-negative patient will be infected given a single $\mathrm{HIV}+$ patient within the CBT treatment population abstains from alcohol (parameter 1.2)

3. The cost of treating a case of HIV for a year (from a provider's perspective), (parameter 1.3)

The parameter 1.1 was taken from a randomized control trial done by Papas et al. [54]. This study found that $69 \%$ of CBT participants reported abstinence after a 90 day follow-up, and $38 \%$ of the usual care control group reported abstinence at follow-up. Parameter 1.1 was found by subtracting the difference between the treatment group and the control group. The parameter 1.2 was found from a simulation model of HIV disease progression and transmission by Braithwaite et al. [36]. Through a 135-article review, Braithwaite et al. identified and modeled three consequences of alcohol-use which increase the incidence of HIV transmission: increased risk of condom non-use, increased risk of ARV non-adherence, and increased STI prevalence. Braithwaite et al.'s model estimated $13 \%$ of new HIV infections in Kenya were attributable to alcohol use.

Parameter 1.3 was found by summing the costs of antiretroviral drugs (ARVs), clinic visits, lab tests, clinic support services, and hospital fixed costs (costs related to cleaners, hospital equipment, etc.). All costs except the cost of ARVs were taken from a cross-sectional survey by Larson et al., which looked at patient level cost data across three different clinics in Kenya [66]. The World Health Organization (WHO) recommends tenofovir/3TC/EFV as a first-line ARV treatment [67], and the annual cost of tenofovir/ $3 \mathrm{TC} / \mathrm{EFV}$ in Kenya was found using the WHO's Global Price Reporting Mechanism [68]. 


\section{Benefit 2: increased labor force and household productivity}

Studies have shown that alcohol consumption is positively correlated with ARV non-adherence; and conversely, that lower levels of alcohol consumption and abstinence are associated with better ARV adherence [7, 69, 70]. CBT-in reducing alcohol consumption-has been identified as a method to increased ARV adherence [71-73]. ARV adherence and its resulting medical and functional benefits, in turn, have been shown to increase labor force participation (LFP) [74-77] and increase household productivity (HP) [78]. Thus, through a mechanism of ARV adherence, CBT can increase LFP and HP. We estimated the monetary benefits of LFP and HP as per person-year values. These monetary benefits were calculated as the multiplicative product of:

1. The likelihood that a CBT-treated patient will exhibit abstinence for a year (same value as in benefit 1, i.e. parameter 1.1). Note that we do not call this parameter 2.1, but parameter 1.1. We also do not name any variables in this paper as parameter 2.1 in order to avoid confusion.

2. The increase in the likelihood that an HIV+ patient who moves from non-abstinence to abstinence behavior will be ARV-adherent. (Parameter 2.2)

3. The additional ARV-related hours worked annually per person from increased LFP/HP (the additional hours for LFP were used to calculate the value of the benefits for LFP, and the additional hours for HP were used calculate the value of the benefits for HP). (Parameter 2.3)

4. The corresponding wage value for the hours measured in parameter 2.3. (Parameter 2.4)

A major challenge in estimating parameters 2.2 and 2.3 was accounting for potential patient differences in ARVadherence and ARV-initiation respectively. In estimating parameter 2.3, in order to take into account different levels of ARV-adherence, multiple levels of ARV-adherence would need to measured and tracked within a Kenyan population. Such data was not available. Patient differences in ARV-treatment initiation times, meanwhile, can potentially bias measurements of parameter 2.3. Those who initiated ARV-treatment before CBT-treatment are likely to exhibit lower positive benefits from increases in ARV-adherence than those who initiated ARVs during CBT-treatment (and would move from no ARV-treatment to full ARV-adherence post-CBT treatment).

We address problems associated with different levels in ARV-adherence in our estimation of parameter 2.2 by looking only at the effect of full ARV-adherence, and categorizing all other levels of adherence as nonadherence. This binary indicator implies that we need only find the effect of abstinence on increasing the likelihood that a patient moves from any given level of ARVadherence below full adherence (i.e. non-adherence) to full adherence, rather than tracking multiple movements across multiple levels of ARV-adherence. Thus parameter 2.2 was found from a cross-sectional survey of 2920 ARV-treated patients from clinics in Cote d'Ivoire, Benin, and Mali by Jaquet et al. [7]. To estimate parameter 2.2, we subtracted the fraction of non-drinkers which were non-adherent from the fraction of hazardous drinkers which were non-adherent.

To deal with potential ARV-initiation-related bias in the estimation of Parameter 2.3, we used results from the individual fixed-effects regressions of studies which measured the effects of ARV-adherence on random samples of Kenyan patients [74, 78]. By measuring the effect of ARVadherence on productivity in a random sample of patients, the ARV-initiation times of the studied population likely resemble our modeled CBT treatment population, and thus the measured effect used in our input of Parameter 2.3 already takes into account the differences in ARV-initiation of our modeled population. We use results from a study by Thirumurthy et al. to measure the LFP hours of parameter 2.3, using coefficients from their regression of LFP on consistent 6-month ARV-adherence [74]. The value of the per person-year values of the gains in LFP was counted for both men and women, because the regression coefficients were found using control groups comprised of patients from randomly selected households from Kenyan census data and the treatment groups comprised of patients from randomly selected households from the Mosoriot health clinic in Kenya. This random selection ensures that although men are more likely to be engaged in labor market activities than women [74], the results take this into account and can be applied across men and women.

The value of the per person-year values of the gains in $\mathrm{HP}$, on the other hand, was counted only for women, as the regression coefficients from which the HP hours of parameter 2.3 was estimated were specific to female household productivity [78]. We assumed that half of our simulated population was female.

The LFP value for parameter 2.4 was found by taking the mean across all monthly minimum wage listings from the Kenyan Ministry of Labor's 2013 Regulation of Wages, and multiplying this number by 12 to yield an annual estimate. Similarly, the HP value for parameter 2.4 was found by taking the mean hourly wage for a house worker across all geographic locations.

\section{Statistical and sensitivity analyses}

To characterize and take into account the potential error of the studies used for the parameters of our base case, we first conducted one-way sensitivity analyses where we changed all inputs, one at a time, across a range of 
values. The value of the bounds of this range was found by taking the $95 \%$ confidence interval (CI) around the base case values; or if the CI was unavailable, the absolute range of values for which the input was observed. In the cases of the cost of CBT rollout per participant, parameter 1.1 and parameter 2.2, literature values for ranges were not available, so we chose a broad range of values around the base case to reasonably test robustness. In addition to the inputs listed in Table 1, we also varied the treatment effect length, the discount rate, and participant transport reimbursement.

Additionally, to further characterize the inherent uncertainty all inputs in Table 1 were simultaneously varied in a Monte Carlo simulation where, for each cohort of participants, data was drawn from the same ranges as in the oneway sensitivity analysis. Simulations assumed a logarithmic (right-skewed) distribution for costs, a normal distribution for inputs whose ranges were CIs (with a standard deviation equal to the standard error used to calculate the CI), and uniform distribution for all other ranges. We ran Monte Carlo simulations with 10,000 replications for each independent cohort of 13,440 participants using multiprocessor Stata 14 [79]. All simulations assumed the base case 3\% discount rate, and the treatment effect length was set to either one, two, three, four, five, or ten years for each set of 10,000 replications. All sets of replications for each treatment effect length are listed in Fig. 3. For both univariate and probabilistic sensitivity analyses, when the treatment effect length was adjusted, the time horizon was also adjusted as well to take into account the final group's benefits across the treatment effect length.

\section{Results}

The overall benefit-cost ratio was 1.13 . Figure 1 summarizes the costs and benefits for the base case CBT implementation (costs are in the first bar labeled in gray, benefits are shown in the second bar labeled in blue). Training costs in the first year were $\$ 158,000$, which were higher than subsequent years, primarily due to personnel costs. However, costs declined across the final four years to about $\$ 94,000$ in year 5 . The total discounted cost over the five-year rollout was approximately $\$ 554,000$. Over the five year period, the average cost-per-participant was $\$ 44$. (Cost breakdowns are presented in Tables 2 and 3). Benefits totaled $\$ 49,000$; $\$ 118,000 ; \$ 137,000 ; \$ 133,000 ; \$ 129,000$; and $\$ 62,000$ in years $1,2,3,4,5$, and 6 respectively. Note that benefits continued in year 6 , despite the costs of the program ending in year 5 . The average annual savings from decreased HIV incidence (benefit 1) was \$11 per patient; and the annual value for increased productivity (benefit 2) was $\$ 14.50$ per patient. The total value of benefit 1 and benefit 2 was estimated to be approximately $\$ 628,000$.

Figure 2 shows the input variables that most affected the base case scenario in one-way sensitivity analyses. For nearly all inputs shown in Fig. 2, CBT remained cost-savings with a benefit-cost ratio greater than 1 . Not pictured in Fig. 2 are values associated with non-drug related inputs associated with parameter 1.3. These four inputs had little effect on the benefit-cost ratio, and when varied across their ranges, yielded benefit-cost ratio ranges of: 1.138 to 1.140 (support services); 1.13 to 1.15 (lab tests); 1.13 to 1.15 (visits); and 1.11 to 1.18 (fixed costs). Also not shown in Fig. 2 is the uncertainty associated with the assumed treatment effect length. When we adjusted our assumption to the treatment effect lasting 1, 5 and 10 years, the benefit-cost ratio changed to $0.58 ; 2.72$; and 5.05 respectively.

In Fig. 3, we further characterize the inherent uncertainty in the parameters by summarizing the probabilistic sensitivity analyses. The results were split into groups based on treatment effect duration; for each group we present separate Monte Carlo simulations with 10,000

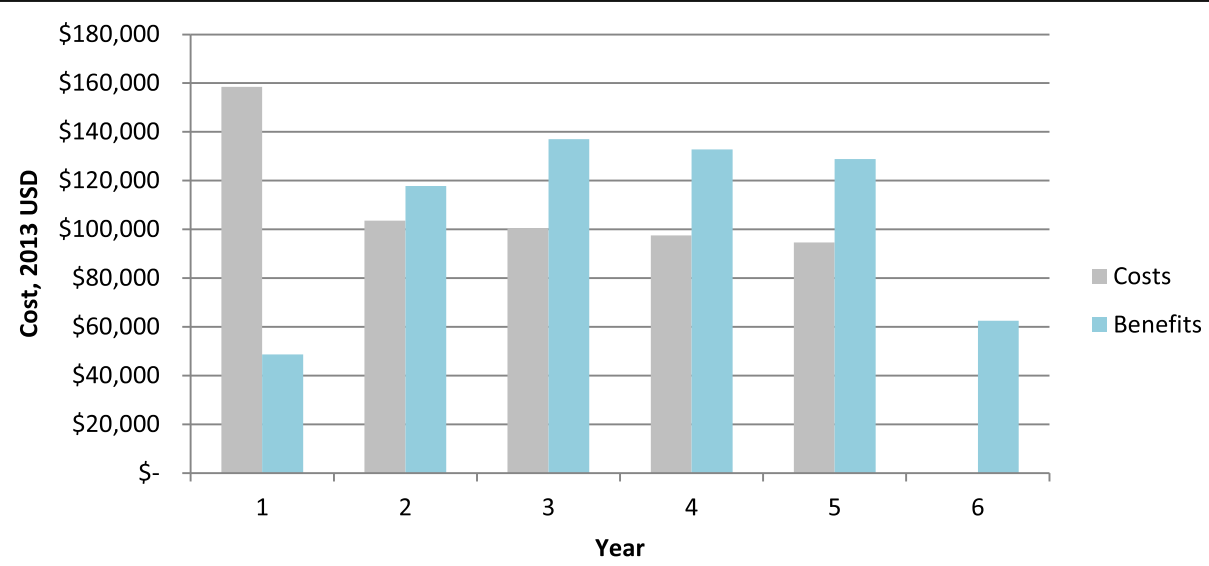

Fig. 1 Costs and potential benefits accrued (in time-discounted 2013 USD). Figure 1 illustrates the monetary costs and potential benefits from a cognitive behavioral therapy which would be used to reduce alcohol abuse among 13,440 persons living with HIV in Kenya. Values of cost and benefits were discounted at a rate of $3 \%$ assuming that they occur at the end of each year, thus costs in year 1 were not discounted 


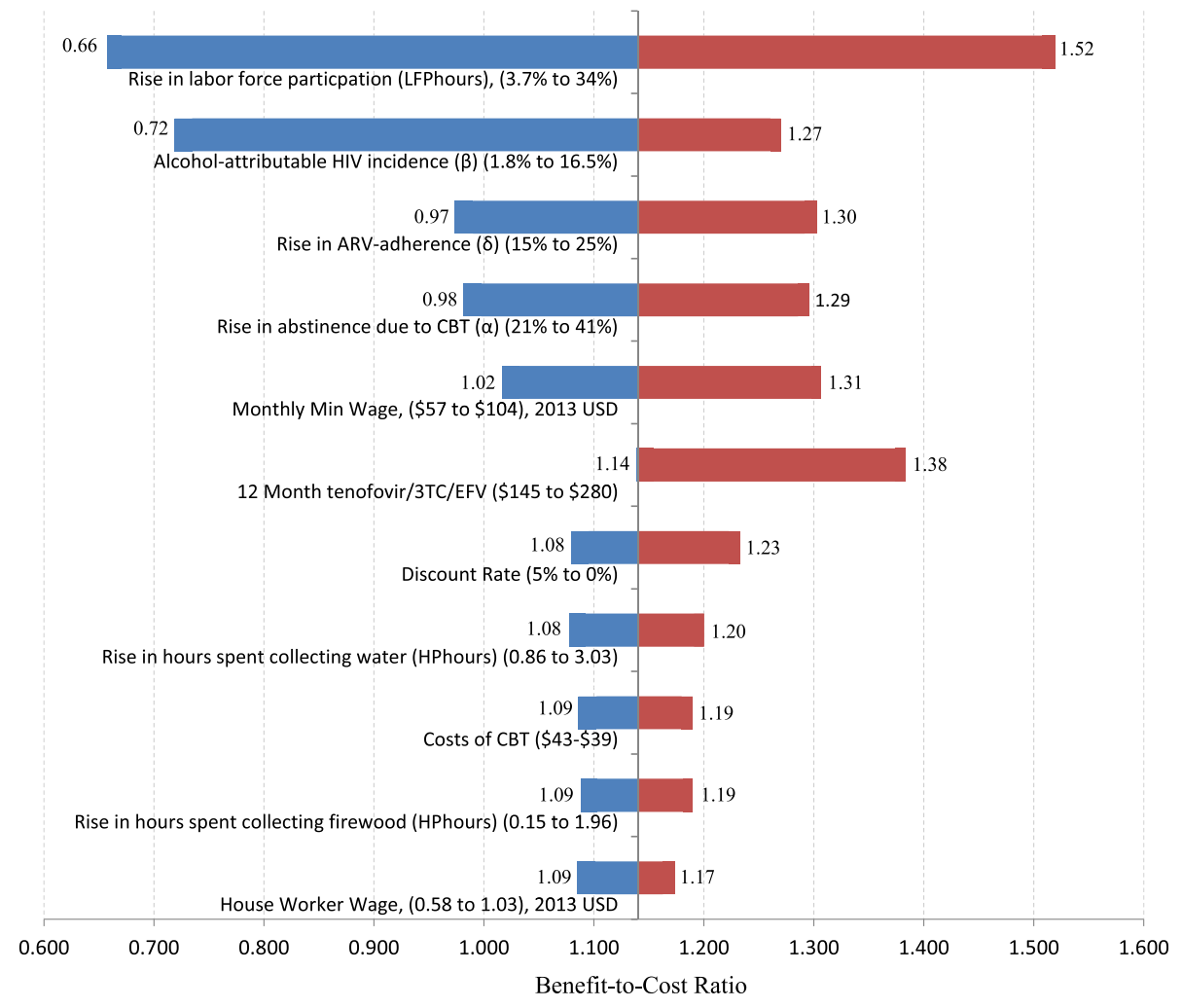

Fig. 2 One-way sensitivity analyses for input variables that most affect the base case results. In the figure above, "Rise in labor force participation" is a measure of the percentage rise in weekly hours worked after ARV treatment; "Alcohol-attributable HIV incidence" is the percentage of HIV incidence attributable to alcohol consumption; "Rise in ARV-adherence" is the Increase in the likelihood that an HIV+ patient which moves from non-abstinence to abstinence behavior will be ARV-adherent; "Rise in abstinence due to CBT" is the Difference between intervention and usual care in percentage of patients reporting abstinence at 90 day follow-up; "Monthly Min Wage" is a measure of the Average Monthly Minimum Wage in Kenya in USD; "12 Month tenofovir/3TC/EFV" is the cost of a 12 Month tenofovir/3TC/EFV drug regimen expressed in 2013 USD; "Rise in hours collecting water" is the increase in female hours spent collecting water in past week; "Costs of CBT" is the cost of the CBT rollout per participant; "Rise in hours spent collecting firewood" is the increase in female hours spent collecting firewood in past week; "House worker min wage" is the Average Hourly Minimum Wage for House Worker. The numbers in the parentheses represent the upper and lower bounds of the sensitivity analysis. The numbers listed at the left and right hand side of the bars represent the benefit to cost ratio which would result from the target variable taking on the corresponding max or min value. Note that the vertical axis is at 1.13 , but that all cost-benefit ratios above 1.0 are cost-saving and thus most variables maintain that CBT is cost saving across the entire range of variables. Ratios rounded to nearest hundredth. Abbreviations: BCR, benefit-to-cost ratio; CBT, cognitive behavioral therapy. The vertical axis intersects the horizontal axis at approximately 1.13

repetitions, each with an independent sample of 13,440 participants. The mean benefit-cost ratio under assumptions that the CBT treatment effect lasted for 1, 2, 3, 4, 5 or 10 years was 0.65 (95\% CI $0.64-0.66)$; 1.28 (95\% CI: $1.26-1.31) ; 1.90$ (95\% CI 1.86-1.94); 2.49 (95\% CI $2.44-$ 2.55); 3.07 (95\% CI 3.01-3.14); and 5.72 (95\% CI: 5.615.84) respectively.

\section{Discussion}

Previous research-which used only health outcomesshowed that CBT was generally cost-effective, but only cost-saving under strict assumptions (i.e., program costs of less than $\$ 1$ per individual) [36, 37]. In this study, across a broad range of assumptions, task-shifted CBT was not only favorable, but even cost-saving from a societal perspective, when we included health and economic productivity benefits. Our base-case scenario showed a benefit-cost ratio of 1.13 when the treatment effects were assumed to last two years; and the benefit-cost ratio increased to 1.90 with a 3-year treatment maintenance scenario.

Our results are consistent with a related exercise which characterized task-shifted CBT for alcohol use reduction in Kenya as cost-effective [37]. However, the extant results go further, showing not only reductions in morbidity and mortality associated with the scale-up, but also monetary cost-savings for the system as a whole in Kenya. Some costs included in our analyses such as specific per-diem rates and housing allowances, are set by the Kenyan government. These are likely not required in other sub-Saharan African countries, so the benefitcost ratio would likely be higher in those settings. The 

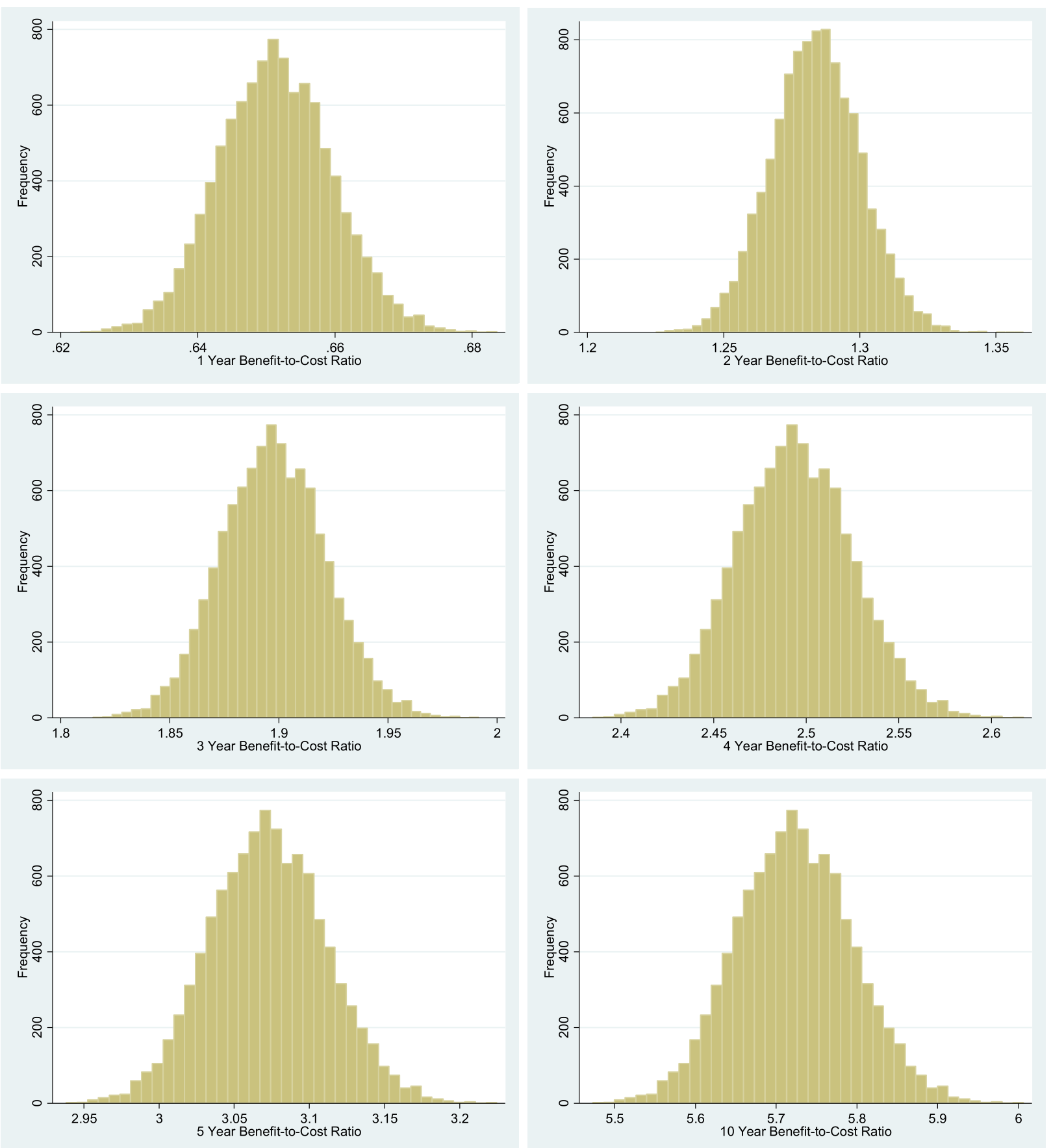

Fig. 3 Distribution of benefit-to-cost ratios from Monte Carlo simulations. Figure 3 shows the results of our probabilistic sensitivity analysis with discounted net benefits. Separate sets of simulations were independently run for the assumption that program effect duration was 1, 2, 4, 5, or 10 years. Each set of simulations was made up of 10000 repetitions done across an independent sample of 13440 participants. Each set of simulations is also shown with a separate graph

provision of transport reimbursement increases the cost of the intervention, but likely enhances the effectiveness of the intervention by facilitating better attendance.

A strength of this study is that the scale-up was constructed using in-depth knowledge and data of the training and implementation of $\mathrm{CBT}$ procedures from two clinical trials. The costing exercise presents a novel and realistic way of shifting the CBT tasks to paraprofessionals in an organized, feasible and scalable manner. The training, enrollment and compensation procedures 
have been implemented in our past and current trials. Furthermore, the potential economic benefits are based on rigorous analyses based in Kenya with the same or similar populations [74, 78], and have been recognized to be more widely applicable [80]. The effect of this approach could support the country's 2010 Alcoholic Drinks Control Act which seeks to tighten legislation against alcohol abuse while also, for the first time, ensuring the right to access to treatment programs [81].

The input parameter most affecting the results was the duration of CBT-alcohol reduction treatment effects. It was difficult to choose a base case scenario because evidence regarding the long-term effect length of CBT for alcohol-use reduction is limited. One reason may be because the length of follow-up of CBT studies is often constrained by the time limits of grant cycles. Despite these limitations, there is reason to believe that CBT treatment effects could be maintained over a long period without major reductions in effectiveness. In a 128-person treatment sample, Kadden and colleagues observed only marginal reductions in treatment effects in alcohol use at 18-month post-treatment follow up; including a group CBT condition [82, 83]. Although we felt a base case of a two-year effect was reasonable, given the uncertainty surrounding the treatment effects, we also conducted sensitivity analyses where the base case treatment effect was adjusted to 1,5 , and 10 years. Our sensitivity analysis showed that our base case results held for treatment effect lengths greater than two years, but at a one-year duration assumption, CBT did not achieve cost-neutrality. This exercise in modeling reveals that while a task-shifted CBT has excellent potential for considerable cost-savings, if treatment effects are particularly short, it is unlikely that CBT will be cost-savings. It may still be highly costeffective (i.e., averting a DALY for less than the per capita GDP), but it may not save money to the government in the long run. Again, very few interventions achieve the status of cost saving [84, 85].

This study has limitations. First, the CBT effects are based on a small pilot study. Thus, we are currently conducting a larger trial, and expect to update the results presented here in future research. Second, due to the limited information regarding the effects of various levels of adherence, we have dichotomized the treatment effect of our modeled CBT as "abstinent" vs. "non-abstinent. It is possible that if continuous data were available regarding the effect of reducing drinking by one drink, then our modeled CBT would be shown to have even greater levels of benefits in terms of ARV adherence and reduced HIV infectivity given the positively correlation between alcohol use and these modeled benefits [7, 31, 36, 37, 64-67, 71-73]. Third, cost-benefit models regarding future cost-savings carry inherent uncertainty as assumptions must be made regarding the consequences of an intervention. As discussed above, the input parameter most affecting CBT treatment cost-neutrality was the CBT treatment effect maintenance. However, to deal with the uncertainty of this and all other variables, we conducted various sensitivity analyses: assumptions regarding the parameters in this model were varied one at a time, as well as simultaneously across ranges presented in the literature.

\section{Conclusion}

A scaled-up task-shifted CBT intervention to reduce alcohol use among HIV+ persons receiving ARVs can be not only cost-effective but also potentially cost-saving in settings such as Kenya, with generalized HIV epidemics and high rates of alcohol use. This analysis can be helpful for other countries planning to use task-shifting of CBT to reduce alcohol use, not only to reduce morbidity and mortality related to HIV disease, but also to generate potential economic gains. In particular, the study demonstrates how ex ante economic evaluation results may be generated such that countries can evaluate the effectiveness of other mental and public health approaches to improving ARV adherence, reducing risk sexual behaviors, and reducing HIV incidence.

\section{Abbreviations \\ 3TC: Lamivudine; AIDS: Acquired immune deficiency syndrome; ARV: Antiretroviral; AUD: Alcohol use disorder; BCR: Benefit-cost ratio; CBA: Cost-benefit analysis; \\ CBT: Cognitive behavioral therapy; Cl: Confidence interval; DALY: Disability-adjusted life year; EFV: Efavirenz; GDP: Gross domestic product; HIV: Human immunodeficiency virus; HP: Household productivity; KES: Kenyan shilling; LFP: Labor force participation; MAT: Medication assisted therapy; USD: United States dollar; WHO: World Health Organization}

\section{Acknowledgment}

We thank the AMPATH clinic staff for facilitating the intervention studies and their help in providing data for this project. We also thank the participants in the intervention studies for providing contributions to this project. The multivariate Monte Carlo simulations were conducted using the high-performance computer cluster at the Center for Computation and Visualization (CCV) at Brown University (ccv.brown.edu).

\section{Funding}

This study was supported in part by grants from NIH/NIAAA: "Alcohol \& HIV in Kenya: Stage 1 Trial of a Peer-led Alcohol Behavior Intervention" (R21 AA016884); and "A Stage 2 cognitive-behavioral trial: Reduce Alcohol First in Kenya Intervention (RAFIKI)" (R01 AA020805) (P.I.: Rebecca Papas, Ph.D.).

Funding from these grants was used in the collection of data related to the costs and effectiveness of the cognitive behavioral therapy mentioned in the manuscript text

\section{Availability of data and materials}

All data is presented in manuscript. Any additional materials or information will be made upon inquiry to corresponding author.

\section{Authors' contributions}

OG and RKP designed the economic study, obtained financing and were in charge of conducting the study. OG and BG operationalized the economic evaluation model and implemented the simulations. BNG, DK and RKP constructed the costing worksheets. RGW and JES contributed to the adjustment of the methods and procedures for the estimation of costs and benefits. All the authors contributed in the conception, writing, critical reading and approval of final article. 


\section{Competing interests}

The authors declare that they have no competing interests.

\section{Consent for publication}

Not applicable.

Ethics approval and consent to participate

Not applicable.

\section{Publisher's Note}

Springer Nature remains neutral with regard to jurisdictional claims in published maps and institutional affiliations.

\section{Author details}

'Brown University School of Public Health, G-S121-7121 South Main Street, Providence, RI 02912, USA. Brown University Alpert Medical School, 222 Richmond Street, Providence, RI 02912, USA. ${ }^{3}$ Moi University \& Moi Teaching and Referral Hospital, Nandi Rd, Eldoret, Kenya. ${ }^{4}$ Edify Youth, St Paul, MN, USA. ${ }^{5}$ Northeastern University, Integrated Initiative for Global Health, 360 Huntington Avenue, 220G RP, Boston, MA 02115, USA. 'Indiana University School of Medicine, Indianapolis, IN, USA. ${ }^{7}$ Department of Psychiatry and Human Behavior, Brown University Alpert Medical School, Providence, RI 02912, USA

\section{Received: 29 December 2015 Accepted: 17 March 2017} Published online: 28 March 2017

\section{References}

1. Rehm J, Mathers C, Popova S, Thavorncharoensap M, Teerawattananon Y, Patra J. Global burden of disease and injury and economic cost attributable to alcohol use and alcohol-use disorders. Lancet. 2009;373(9682):2223-33.

2. WHO. Global Status Report on Alcohol and Health 2014. Geneva: World Health Organization (WHO); 2014

3. Bass JK, Bornemann TH, Burkey M, Chehil S, Chen L, Copeland JR, Eaton WW, Ganju V, Hayward E, Hock RS, et al. A United Nations General Assembly Special Session for mental, neurological, and substance use disorders: the time has come. PLoS Med. 2012;9(1), e1001159.

4. Collins PY, Insel TR, Chockalingam A, Daar A, Maddox YT. Grand challenges in global mental health: integration in research, policy, and practice. PLOS Med. 2013;10(4), e1001434.

5. Collins PY, Patel V, Joestl SS, March D, Insel TR, Daar AS, Anderson W, Dhansay MA, Phillips A, Shurin S, et al. Grand challenges in global mental health. Nature. 2011;475(7354):27-30.

6. Nakimuli-Mpungu E, Bass JK, Alexandre P, Mills EJ, Musisi S, Ram M, Katabira E, Nachega JB. Depression, Alcohol Use and Adherence to Antiretroviral Therapy in Sub-Saharan Africa: A Systematic Review. AIDS Behav. 2012;16(8):2101-18.

7. Jaquet $A$, Ekouevi DK, Bashi J, Aboubakrine M, Messou E, Maiga M, Traore HA, Zannou MD, Guehi C, Ba-Gomis FO, et al. Alcohol use and nonadherence to antiretroviral therapy in HIV-infected patients in West Africa. Addiction. 2010;105(8):1416-21.

8. Scribner R, Theall KP, Simonsen N, Robinson W. HIV Risk and the Alcohol Environment Advancing an Ecological Epidemiology for HIV/AIDS. Alcohol Res Health. 2010;33(3):179-83.

9. Kalichman SC, Simbayi LC, Kaufman M, Cain D, Jooste S. Alcohol use and sexual risks for HIV/AIDS in sub-Saharan Africa: Systematic review of empirical findings. Prev Sci. 2007:8(2):141-51.

10. Braithwaite RS, Conigliaro J, Roberts MS, Shechter S, Schaefer A, McGinnis K Rodriguez MC, Rabeneck L, Bryant K, Justice AC. Estimating the impact of alcohol consumption on survival for HIV+ individuals. AIDS Care. 2007;19(4):459-66.

11. Bryant KJ. Expanding research on the role of alcohol consumption and related risks in the prevention and treatment of HIV/AIDS. Subst Use Misuse. 2006;41(10-12):1465-507.

12. WHO/UNAIDS/UNICEF. Progress report 2011: Global HIV/AIDS response. Epidemic update and health sector - progress towards Universal Access. Geneva: World Health Organization (WHO); 2011.

13. UNAIDS. Report on the global AIDS epidemic 2012. Geneva: United National Joint Programme on HIV/AIDS (UNAIDS); 2012.

14. UNAIDS. Getting to Zero: 2011-2015 Strategy. Geneva: United Nations Joint Programme on HIV/AIDS (UNAIDS); 2010.

15. Cohen MS, Chen YQ, McCauley M, Gamble T, Hosseinipour MC Kumarasamy N, Hakim JG, Kumwenda J, Grinsztejn B, Pilotto JH, et al.
Prevention of HIV-1 infection with early antiretroviral therapy. N Engl J Med. 2011:365(6):493-505.

16. Karim SS, Karim QA. Antiretroviral prophylaxis: a defining moment in HIV control. Lancet. 2011;378(9809):e23-5.

17. Simoni JM, Kurth AE, Pearson CR, Pantalone DW, Merrill JO, Frick PA. Self-report measures of antiretroviral therapy adherence: A review with recommendations for HIV research and clinical management. AIDS Behav. 2006;10(3):227-45.

18. Glass TR, De Geest $S$, Weber R, Vernazza PL, Rickenbach M, Furrer H, Bernasconi E, Cavassini M, Hirschel B, Battegay M, et al. Correlates of self-reported nonadherence to antiretroviral therapy in HIV-infected patients: the Swiss HIV Cohort Study. J Acquir Immune Defic Syndr. 2006;41(3):385-92.

19. Kalichman S, Simbayi L, Vermaak R, Cain D, Smith G, Mthebu J, Jooste S. Randomized Trial of a Community-based Alcohol-related HIV Risk-reduction Intervention for Men and Women in Cape Town South Africa. Ann Behav Med. 2008;36(3):270-9.

20. Kalichman SC, Simbayi LC, Cain D, Jooste S. Alcohol expectancies and risky drinking among men and women at high-risk for HIV infection in Cape Town South Africa. Addict Behav. 2007;32(10):2304-10.

21. Braithwaite RS, Bryant KJ. Influence of alcohol consumption on adherence to and toxicity of antiretroviral therapy and survival. Alcohol Res Health. 2010;33(3):280-7.

22. Gmel G, Shield KD, Rehm J. Developing a method to derive alcoholattributable fractions for HIV/AIDS mortality based on alcohol's impact on adherence to antiretroviral medication. Popul Health Metrics. 2011;9(1):5.

23. Azar MM, Springer SA, Meyer JP, Altice FL. A systematic review of the impact of alcohol use disorders on HIV treatment outcomes, adherence to antiretroviral therapy and health care utilization. Drug Alcohol Depend. 2010;112(3):178-93.

24. Justice AC, Lasky E, McGinnis KA, Skanderson M, Conigliaro J, Fultz SL, Crothers K, Rabeneck L, Rodriguez-Barradas M, Weissman SB, et al. Medical disease and alcohol use among veterans with human immunodeficiency infection: A comparison of disease measurement strategies. Med Care. 2006; 44(8 Suppl 2):S52-60.

25. Waweru M, Kamau A, Matogo J. Situational analysis of alcohol consumption among high school students: a baseline survey. SCAD: Nairobi; 2011.

26. American Psychiatric Association., American Psychiatric Association. DSM-5 Task Force. Diagnostic and statistical manual of mental disorders : DSM-5. 5th ed. Washington, D.C: American Psychiatric Association; 2013.

27. Woolf-King SE, Maisto SA. Alcohol use and high-risk sexual behavior in Sub-Saharan Africa: a narrative review. Arch Sex Behav. 2011;40(1):17-42.

28. Young SV, Wood E, Dong H, Kerr T, Hayashi K. Daily alcohol use as an independent risk factor for HIV seroconversion among people who inject drugs. Addiction. 2016;111(8):1360-5. doi:10.1111/add.13256.

29. WHO. mhGAP: Mental Health Gap Action Programme: scaling up care for mental, neurological and substance use disorders. Geneva: World Health Organization (WHO); 2008.

30. Kiima D. Report of the World Mental Health Day held on 31st October 2008 at Mathari Hospital - Nairobi. Ministry of Health: Nairobi; 2008.

31. KNCHR. The Silenced Minds: The Systemic Neglect of the Mental Health System in Kenya. Kenya National Commission on Human Rights: Nairobi; 2011.

32. Kiima D, Jenkins R. Mental health policy in Kenya -an integrated approach to scaling up equitable care for poor populations. Int J Ment Health Sy. 2010;4.

33. Obot IS. Alcohol use and related problems in sub-Saharan Africa. Afr J Drug Alcohol Stud. 2006;5(1):17-26.

34. Baingana FK, Alem A, Jenkins R. Mental health and the abuse of alcohol and controlled substances. In: Jamison DT, Feachem RG, Makgoba MW, editors. Disease and mortality in Sub-Saharan Africa. 2nd ed. Washington, D.C: World Bank; 2006.

35. Shaffer DN, Njeri R, Justice AC, Odero WW, Tierney WM. Alcohol abuse among patients with and without HIV infection attending public clinics in western Kenya. East Afr Med J. 2004;81:594-8.

36. Braithwaite RS, Nucifora KA, Kessler J, Toohey C, Mentor SM, Uhler LM, Roberts MS, Bryant K. Impact of Interventions Targeting Unhealthy Alcohol Use in Kenya on HIV Transmission and AIDS-Related Deaths. Alcohol Clin Exp Res. 2014;38(4):1059-67.

37. Braithwaite RS, Nucifora KA, Kessler J, Toohey C, Li L, Mentor SM, Uhler LM, Roberts MS, Galvani A, Bryant K. How Inexpensive Does an Alcohol Intervention in Kenya Need to be in Order to Deliver Favorable Value by Reducing HIV-Related Morbidity and Mortality? J Acquir Immune Defic Syndr. 2014;66(2):e54-8.

38. WHO. Task Shifting: Rational Redistribution of Tasks Among Health Workforce Teams: Global Recommendations and Guidelines. Geneva: World Health Organization (WHO); 2008. 
39. Frenk J, Chen L, Bhutta ZA, Cohen J, Crisp N, Evans T, Fineberg H, Garcia P, Ke $Y$, Kelley $P$, et al. Health professionals for a new century: transforming education to strengthen health systems in an interdependent world. Lancet. 2010;376(9756):1923-58.

40. Callaghan M, Ford N, Schneider H. A systematic review of task- shifting for HIV treatment and care in Africa. Hum Resour Health. 2010;8:8.

41. Mdege ND, Chindove S, Ali S. The Effectiveness and Cost Implications of Task-Shifting in the Delivery of Antiretroviral Therapy to HIV-Infected Patients: A Systematic Review. Health Policy Plan. 2013;28(3):223-36.

42. Jenkins R, Kiima D, Njenga F, Okonji M, Kingora J, Kathuku D, Lock S Integration of mental health into primary care in Kenya. World Psychiatry. 2010;9(2):118-20.

43. Mwandi Z, Murphy A, Reed J, Chesang K, Njeuhmeli E, Agot K, Llewellyn E, Kirui C, Serrem K, Abuya I, Loolpapit M, Mbayaki R, Kiriro N, Cherutich P, Muraguri N, Motoku J, Kioko J, Knight N, Bock N. Voluntary medical male circumcision: translating research into the rapid expansion of services in Kenya, 2008-2011. PLoS Med. 2011;8(11):e1001130. doi:10.1371/journal. pmed. 1001130.

44. Muula AS, Ngulube TJ, Siziya S, Makupe CM, Umar E, Prozesky HW, Wiysonge CS, Mataya RH. Gender distribution of adult patients on highly active antiretroviral therapy (HAART) in Southern Africa: a systematic review. BMC Public Health. 2007;7:63

45. Ochieng-Ooko V, Ochieng D, Sidle JE, Holdsworth M, Wools-Kaloustian K, Siika AM, Yiannoutsos CT, Owiti M, Kimaiyo S, Braitstein P. Influence of gender on loss to follow-up in a large HIV treatment programme in western Kenya. B World Health Organ. 2010;88(9):681-8.

46. Bryant KJ, Nelson S, Braithwaite RS, Roach D. Integrating HIV/AIDS and Alcohol Research. Alcohol Res Health. 2010;33(3):167-78.

47. Papas RK, Sidle JE, Martino S, Baliddawa JB, Songole R, Omolo OE, Gakinya BN, Mwaniki MM, Adina JO, Nafula T, et al. Systematic cultural adaptation of cognitive-behavioral therapy to reduce alcohol use among HIV-infected outpatients in western Kenya. AIDS Behav. 2010;14(3):669-78.

48. Kadden RM, Cooney NL, Getter H, Litt MD. Matching alcoholics to coping skills or interactional therapies: posttreatment results. J Consult Clin Psychol. 1989;57(6):698-704.

49. Miller WR, Zweben J, Johnson WR. Evidence-based treatment: why, what, where, when, and how? J Subst Abus Treat. 2005;29(4):267-76.

50. Jones DL, Ross D, Weiss SM, Bhat G, Chitalu N. Influence of partner participation on sexual risk behavior reduction among HIV-positive Zambian women. J Urban Health. 2005:82(3 Suppl 4):iv92-iv100.

51. Osinowo HO, Olley BO, Adejumo AO. Evaluation of the effect of cognitive therapy on perioperative anxiety and depression among Nigerian surgical patients. West Afr J Med. 2003;22(4):338-42.

52. Anton RF, O'Malley SS, Ciraulo DA, Cisler RA, Couper D, Donovan DM, Gastfriend DR, Hosking JD, Johnson BA, LoCastro JS, et al. Combined pharmacotherapies and behavioral interventions for alcohol dependence: the COMBINE study: a randomized controlled trial. Jama. 2006;295(17):2003-17.

53. Lee JD, Grossman E, Huben L, Manseau M, McNeely J, Rotrosen J, Stevens D, Gourevitch MN. Extended-release naltrexone plus medical management alcohol treatment in primary care: findings at 15 months. J Subst Abus Treat. 2012;43(4):458-62.

54. Papas RK, Sidle JE, Gakinya BN, Baliddawa JB, Martino S, Mwaniki MM, Songole R, Omolo OE, Kamanda AM, Ayuku DO, et al. Treatment outcomes of a stage 1 cognitive-behavioral trial to reduce alcohol use among human immunodeficiency virus-infected out-patients in western Kenya. Addiction. 2011;106(12):2156-66.

55. Meyer-Rath G, Pienaar J, Brink B, van Zyl A, Muirhead D, Grant A, Churchyard G, Watts C, Vickerman P. The Impact of Company-Level ART Provision to a Mining Workforce in South Africa: A Cost-Benefit Analysis. PLoS Med. 2015;12(9), e1001869.

56. Brent RJ. A social cost-benefit criterion for evaluating Voluntary Counseling and Testing with an application to Tanzania. Health Econ. 2010;19(2):154-72.

57. Owen L, Morgan A, Fischer A, Ellis S, Hoy A, Kelly MP. The cost-effectiveness of public health interventions. J Public Health (Oxf). 2012;34(1):37-45.

58. Drummond M, Drummond M. Methods for the economic evaluation of health care programmes. 3rd ed. Oxford; New York: Oxford University Press; 2005.

59. Papas RK, Gakinya BN, Baliddawa JB, Martino S, Bryant KJ, Meslin EM, Sidle JE. Ethical issues in a stage 1 cognitive-behavioral therapy feasibility study and trial to reduce alcohol use among HIV-infected outpatients in western Kenya. J Empir Res Human Res Ethics. 2012;7(3):29-37.
60. Kenya National Bureau of Statistics. Consumer Price Index [http://www.knbs.or. ke/index.php?option=com_phocadownload\&view=category\&id=8\&ltemid= 562]. Accessed 20 Mar 2017.

61. The World Bank. Official exchange rate (LCU per US\$, period average). 2014

62. Hahn JA, Woolf-King SE, Muyindike W. Adding fuel to the fire: alcohol's effect on the HIV epidemic in Sub-Saharan Africa. Curr HIV/AIDS Rep. 2011; 8(3):172-80.

63. Pithey A, Parry C. Descriptive systematic review of Sub-Saharan African studies on the association between alcohol use and HIV infection. SAHARA J. 2009;6(4):155-69.

64. Van Tieu H, Koblin BA. HIV, alcohol, and noninjection drug use. Curr Opin HIV AIDS. 2009;4(4):314-8.

65. Woolf-King S, Steinmaus CM, Reingold AL, Hahn JA. An update on alcohol use and risk of HIV infection in sub-Saharan Africa: Meta-analysis and future research directions. Int J Alcohol Drug Res. 2013;2(1):99-110.

66. Larson BA, Bii M, Henly-Thomas S, McCoy K, Sawe F, Shaffer D, Rosen S. ART treatment costs and retention in care in Kenya: a cohort study in three rural outpatient clinics. J Int AIDS Soc. 2013;16:18026.

67. WHO. Consolidated guidelines on the use of antiretroviral drugs for treating and preventing HIV infection. Geneva: World Health Organization (WHO); 2013.

68. World Health Organization. Global Price Reporting Mechanism for HIV, tuberculosis and malaria [http://www.who.int/hiv/amds/gprm/en/]. Last accessed: 20 March 2017.

69. Samet JH, Horton NJ, Meli S, Freedberg KA, Palepu A. Alcohol consumption and antiretroviral adherence among HIV-infected persons with alcohol problems. Alcohol Clin Exp Res. 2004;28(4):572-7.

70. Chesney MA. Factors affecting adherence to antiretroviral therapy. Clin Infect Dis. 2000;30 Suppl 2:S171-6.

71. Kekwaletswe $\subset$ T, Morojele NK. Alcohol use, antiretroviral therapy adherence, and preferences regarding an alcohol-focused adherence intervention in patients with human immunodeficiency virus. Patient Prefer Adherence. 2014;8:401-13.

72. Enriquez M, McKinsey DS. Strategies to improve HIV treatment adherence in developed countries: clinical management at the individual level. HIV/AIDS (Auckland, NZ). 2011;3:45-51.

73. Kader R, Govender R, Seedat S, Koch JR, Parry C. Understanding the Impact of Hazardous and Harmful Use of Alcohol and/or Other Drugs on ARV Adherence and Disease Progression. PLoS One. 2015;10(5), e0125088.

74. Thirumurthy H, Zivin JG, Goldstein M. The Economic Impact of AIDS Treatment: Labor Supply in Western Kenya. J Hum Resour. 2008;43(3):511-52.

75. Rosen S, Larson B, Rohr J, Sanne I, Mongwenyana C, Brennan AT, Galarraga O. Effect of antiretroviral therapy on patients' economic well being: five-year follow-up. AIDS (London, England). 2014;28(3):417-24.

76. Thirumurthy H, Zivin JG. Health and labor supply in the context of HIV/AIDS the long-run economic impacts on antiretroviral therapy(). Econ Dev Cult Chang. 2012;61(1):73-96

77. Venkataramani AS, Thirumurthy H, Haberer JE, li YB, Siedner MJ, Kembabazi A, Hunt PW, Martin JN, Bangsberg DR, Tsai AC. CD4+ cell count at antiretroviral therapy initiation and economic restoration in rural Uganda. AIDS (London, England). 2014;28(8):1221-6.

78. d'Adda G, Goldstein M, Zivin JG, Nangami M, Thirumurthy H. ARV Treatment and Time Allocation to Household Tasks: Evidence from Kenya. Afr Dev Rev. 2009;21(1):180-208.

79. Cameron AC, Trivedi PK. Microeconometrics using Stata. College Station, Tex: Stata Press; 2010.

80. Thirumurthy H, Galarraga O, Larson B, Rosen S. HIV treatment produces economic returns through increased work and education, and warrants continued US support. Health Aff (Millwood). 2012;31(7):1470-7.

81. Parliament of Kenya. Alcoholic Drinks Control Act. In: No 4 of 2010 (Rev). Kenya: National Council for Law Reporting with the Authority of the Attorney-General; 2012.

82. Litt MD, Kadden RM, Cooney NL, Kabela E. Coping skills and treatment outcomes in cognitive-behavioral and interactional group therapy for alcoholism. J Consult Clin Psychol. 2003;71(1):118-28.

83. Kadden RM, Litt MD, Cooney NL, Kabela E, Getter H. Prospective matching of alcoholic clients to cognitive-behavioral or interactional group therapy. J Stud Alcohol. 2001;62(3):359-69.

84. Rappange DR, Brouwer WB, Rutten FF, van Baal PH. Lifestyle intervention: from cost savings to value for money. J Public Health (Oxf). 2010;32(3):440-7.

85. Cohen JT, Neumann PJ, Weinstein MC. Does preventive care save money? Health economics and the presidential candidates. N Engl J Med. 2008; 358(7):661-3. 
86. Braithwaite RS, Nucifora KA, Kessler J, Toohey C, Mentor SM, Uhler LM, Roberts MS, Bryant K. Impact of interventions targeting unhealthy alcohol use in Kenya on HIV transmission and AIDS-related deaths. Alcohol Clin Exp Res. 2014;38(4):1059-67. doi:10.1111/acer.12332.

87. Government of Kenya. The Regulation of Wages Order, 2013 [http://admin. theiguides.org/Media/Documents/10Legal\%20Notice\%20196\%20and\%20197 \%202013\%20Minimum\%20Wage.pdf] Accessed 20 Mar 2017.

Submit your next manuscript to BioMed Central and we will help you at every step:

- We accept pre-submission inquiries

- Our selector tool helps you to find the most relevant journal

- We provide round the clock customer support

- Convenient online submission

- Thorough peer review

- Inclusion in PubMed and all major indexing services

- Maximum visibility for your research

Submit your manuscript at www.biomedcentral.com/submit 